03,04,05,06

\title{
Электрофизические и диэлектрические свойства поликристаллов железо-иттриевого феррита-граната, полученных по технологии радиационно-термического спекания
}

\author{
(C) В.Г. Костишин ${ }^{1}$, Р.И. Шакирзянов ${ }^{1}$, А.Г. Налогин ${ }^{2}$, С.В. Щербаков ${ }^{2}$, И.М. Исаев ${ }^{1}$, М.А. Немирович ${ }^{1}$, \\ М.А. Михайленко ${ }^{3}$, М.В. Коробейников ${ }^{4}$, М.П. Мезенцева ${ }^{1}$, Д.В. Салогуб ${ }^{1}$
}

${ }^{1}$ Национальный исследовательский технологический университет „МИСиС“, Москва, Россия

${ }^{2}$ АО НПП „Исток им. Шокина“,

Фрязино, Московсковская обл., Россия

${ }^{3}$ Институт химии твердого тела и механохимии СО РАН,

Новосибирск, Россия

${ }^{4}$ Институт ядерной фиизики им. Б.И. Будкера СО РАН,

Новосибирск, Россия

E-mail: drvgkostishyn@mail.ru

Поступила в Редакцию 26 октября 2020 г.

В окончательной редакции 26 октября 2020 г.

Принята к публикации 28 октября 2020 г.

\begin{abstract}
Рассмотрены электрофизические и диэлектрические свойства поликристаллических образцов железоиттриевого граната, полученных по технологии радиационно-термического спекания в пучке быстрых электронов. В диапазоне частот от $25 \mathrm{~Hz}$ до $1 \mathrm{MHz}$ при н. у. измерены спектры комплексной диэлектрической проницаемости, тангенса угла диэлектрических потерь и проводимости на переменном токе. Для сравнения помимо частотных измерений были выполнены измерения сопротивления на постоянном токе. Также получены температурные зависимости вышеуказанных параметров при частотах 1 и $100 \mathrm{kHz}$ в диапазоне температур $25-300^{\circ} \mathrm{C}$. По температурным зависимостям электропроводности в координатах Аррениуса определены энергии активации процессов проводимости на переменном и постоянном электрическом токе. Показано, что с увеличением температуры спекания с 1300 до $1450^{\circ} \mathrm{C}$ электрофизические параметры достигают значений, характерных для образцов, выполненных по традиционной керамической технологии.
\end{abstract}

Ключевые слова: железоиттриевый гранат, технология радиационно-термического спекания, температура спекания, керамическая технология, диэлектрическая проницаемость, энергия активации, электропроводность.

DOI: 10.21883/FTT.2021.03.50586.230

\section{1. Введение}

Ферриты со структурой граната нашли применение в технике сверхвысоких частот (СВЧ) еще с середины XX века ввиду их уникальных электрофизических характеристик: высокой частоты ферромагнитного резонанса (ФМР) - 8-12 GHz; малой ширины линии ФМР 0.2-0.5 Ое (на монокристалле); низких значений тангенса угла диэлектрических потерь [1]. Благодаря вышеуказанным свойствам феррогранатов возможно создание высококачественных СВЧ-вентилей, циркуляторов, фазовращателей с низким уровнем потерь на основе железо-иттриевого граната (ЖИГ) $\mathrm{Y}_{3} \mathrm{Fe}_{5} \mathrm{O}_{12}$. В настоящее время уровень технологии производства ЖИГ позволяет создавать поликристаллические ферриты хорошего качества с помощью твердофазного синтеза (керамической технологии). Несмотря на распространенность и широкое применение этого метода производство ферритовых изделий часто сопряжено с большими трудностями, так как технологический процесс состоит из большого количества этапов и крайне трудоемок. По этой причине производственные факторы могут в сильной степени влиять на воспроизводимость магнитных параметров ферритовых изделий из ЖИГ от партии к партии. В настоящее время потенциальной возможностью модернизации керамической технологии изготовления ферритов является применение радиационно-термического спекания (РТС) [2-6]. Метод РТС может потенциально заменить традиционно использующйся метод термического спекания в печи резистивного нагрева, имеющий такие недостатки как большое время спекания и наличие градиента температуры, приводящие к разбросу характеристик образцов в зависимости от местоположения в печи при спекании.

Помимо использования ЖИГ в СВЧ-приборах учеными и инженерами предлагались новые способы их применения: антенны на диэлектрических резонаторах [7], магнитооптическая память [8], биосовместимые пленки для биоантенн [9], основа для радиопоглощающих нанокомпозитов [10]. В связи с этим, применение РТСтехнологии для получения феррогранатов приобретает дополнительные актуальность и научный интерес. 
Настоящая работа посвящена исследованию электрофизических и диэлектрических характеристик ЖИГ, полученных с применением технологии РТС. Диэлектрические характеристики регистрировались методом диэлектрической спектроскопии в радиочастотном диапазоне. Данный метод достаточно информативен при изучении структуры керамики $[11,12]$, а также может дать значения важных электрофизических параметров. Последнее особенно актуально ввиду того, что метод РТС является относительно новым и возможность прогнозирования физических свойств материалов на основе ЖИГ при применении данного метода - важная технологическая задача. Ранее [13], с помощью мёссбауэровских исследований образцов ЖИГ, полученных методом РТС, было установлено, что оптимальной температурой спекания является температура $1350-1400^{\circ} \mathrm{C}$ и время спекания от 40 до $60 \mathrm{~min}$. При этом сравнение РТСобразцов с образцами, изготовленными по керамической технологии, показало, что технология РТС позволяет получить образцы лучшего качества. В другой работе [14] изучались магнитные свойства поликристаллических образцов ЖИГ, полученных методом РТС. Было продемонстрировано, что с ростом температуры РТС от 1300 до $1450^{\circ} \mathrm{C}$ форма и параметры петли магнитного гистерезиса приближаются к характерным для качественного поликристалла $\mathrm{Y}_{3} \mathrm{Fe}_{5} \mathrm{O}_{12}$. СВЧ спектры ЖИГ в диапазоне частот $0.01-7 \mathrm{GHz}$ изучались в работе [15]. Авторы отмечают, что с изменением температуры спекания частотные положения пиков действительной и мнимой частей магнитной проницаемости изменяются, а поглощающие свойства у РТС-поликристаллов выше, чем у образцов, полученных по обычной керамической технологии.

\section{2. Объекты исследования и методика эксперимента}

Образцы ЖИГ были изготовлены путем спекания в пучке быстрых электронов на импульсном линейном ускорителе ИЛУ-6 сырых заготовок, полученных по традиционной керамической технологии (КТ). Более детальное описание методики изготовления исследуемых образцов приведено в работах [13-15]. Полученные образцы были нарезаны на пластины, отшлифованы и отполированы. Толщина пластин после механической обработки составила $\sim 200 \mu \mathrm{m}$.

Для удобства образцам были присвоены номера, согласно таблице, в которой представлена информация о технологических режимах образцов $\mathrm{Y}_{3} \mathrm{Fe}_{5} \mathrm{O}_{12}$, полученных методом РТС (скорость спекания $50^{\circ} \mathrm{C} / \mathrm{min}$ ). Для сравнения по керамической технологии был синтезирован образец при температуре спекания $1500^{\circ} \mathrm{C}$ в течение десяти $h$.

Для изучения электрофизических параметров ферритов на поверхности полированных пластин соосно наносились электроды на основе InGa-эвтектики в виде окружностей $\varnothing \sim 2 \mathrm{~mm}$. Определение сопротивления на постоянном токе проводилось путем измерения
Технологические режимы спекания образцов

\begin{tabular}{|c|c|c|}
\hline $\begin{array}{c}\text { № } \\
\text { образца }\end{array}$ & $\begin{array}{c}\text { Температура } \\
\text { спекания } T,{ }^{\circ} \mathrm{C}\end{array}$ & $\begin{array}{c}\text { Время } \\
\text { спекания } t, \min \end{array}$ \\
\hline 1 & 1300 & 60 \\
\hline 2 & 1350 & 60 \\
\hline 3 & 1400 & 40 \\
\hline 4 & 1450 & 5 \\
\hline 5 & 1450 & 30 \\
\hline $6^{*}$ & 1500 & 600 \\
\hline
\end{tabular}

Пр и м е ч а н и е. Образец, помеченный *, изготавливался по стандартной КТ.

вольтамперных характеристик (BAX) на электрометре Keithley-6514 с рабочим диапазоном по току от 20 до $200 \mu \mathrm{A}$. Для измерения электрофизических свойств на переменном токе использовался RLC-метр E7-20 с диапазоном рабочих частот в диапазоне от $25 \mathrm{~Hz}$ до $1 \mathrm{MHz}$.

Также были исследованы температурные зависимости электрофизических параметров на постоянном токе в диапазоне температур от 20 до $300^{\circ} \mathrm{C}$. Во время исследования температурной зависимости для минимизации внешних помех образцы помещались в печь, оборудованную защитным экраном. Термопара, с помощью которой отслеживалась температура в печи, представляла собой сплав хромель-алюмель.

\section{3. Результаты экспериментов}

\section{1. Измерения на постоянном токе}

Измерения BAX на постоянном токе при н. у. показали, что в области напряжений 10-100 V для всех образцов зависимость тока от приложенного напряжения бы-

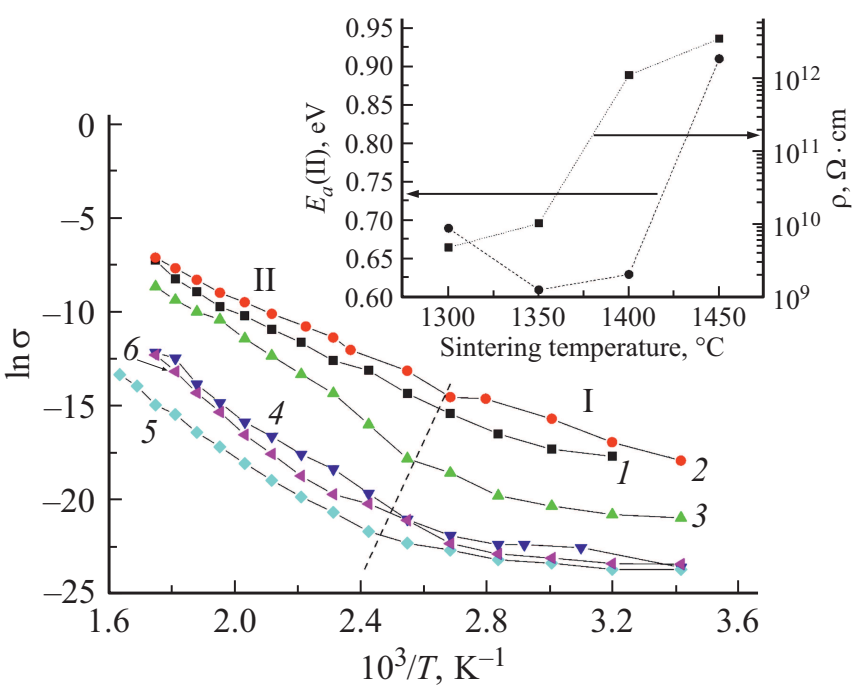

Рис. 1. Зависимость удельной электропроводимости от температуры в координатах Аррениуса для образцов 1-6. На вставке зависимость энергии активации участка II и сопротивления на постоянном токе при н.у. от температуры РТС. 

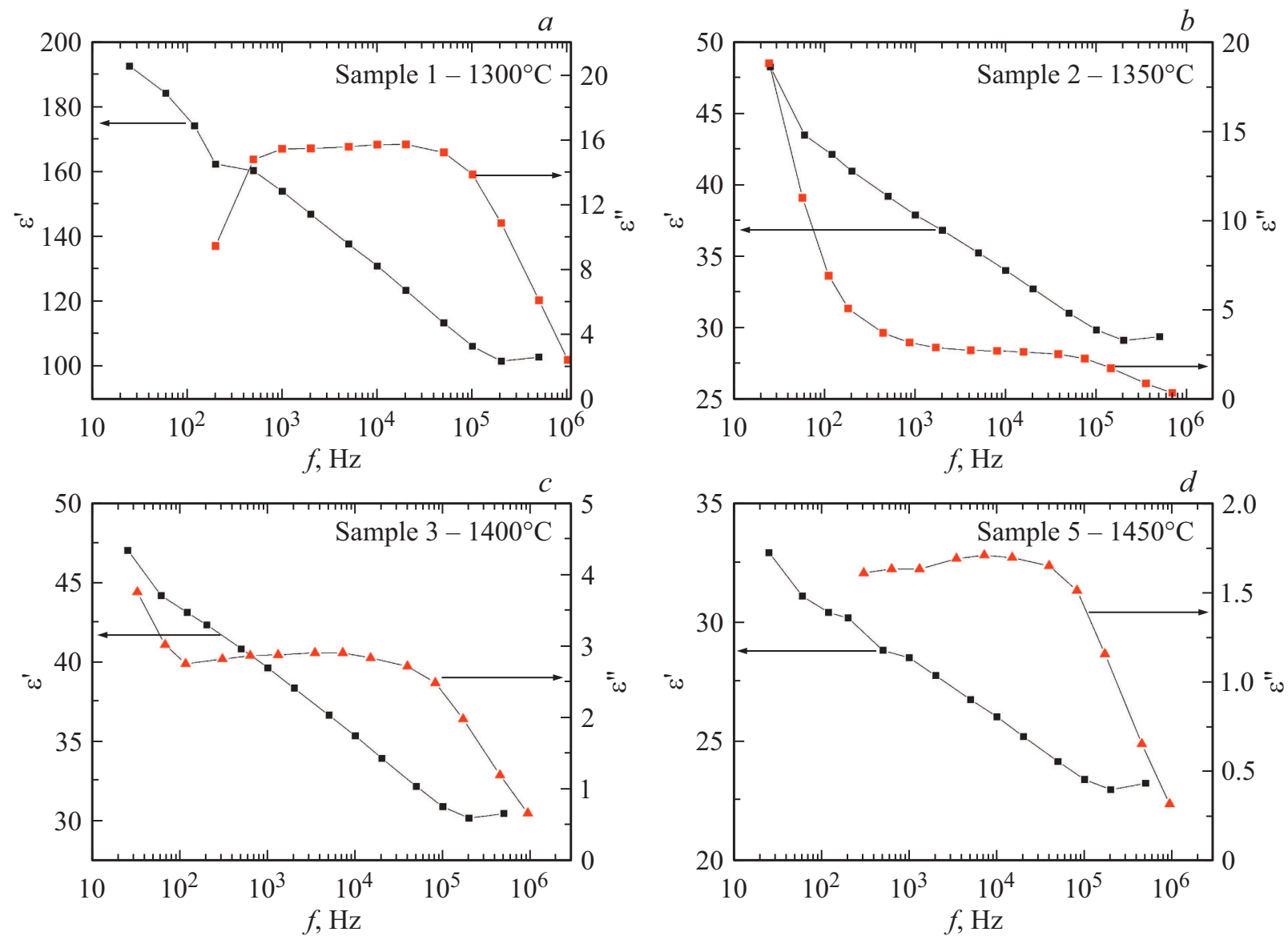

Рис. 2. Спектры действительной и мнимой частей диэлектрической проницаемости при н.у. для РТС ЖИГ: $a$ - температура спекания $1300^{\circ} \mathrm{C}$ (образец 1$) ; b$ - температура спекания $1350^{\circ} \mathrm{C}$ (образец 2 ); $c$ - температура спекания $1400^{\circ} \mathrm{C}($ образец 3 ); $d$ - температура спекания $1450^{\circ} \mathrm{C}$ (образец 5).

ла линейной. Результаты измерения электропроводности в температурном диапазоне $25-300^{\circ} \mathrm{C}$ представлены на рис. 1. На вставке приведены значения сопротивления при $20^{\circ} \mathrm{C}$, а также энергия активации процесса проводимости, рассчитанная по формуле Аррениуса

$$
\sigma=\sigma_{0} \exp \left(-E_{a} / k T\right)
$$

где $\sigma$ - удельная электроповодность, $E_{a}-$ энергия активации.

\section{2. Измерения на переменном токе}

Спектры действительной и мнимой частей диэлектрической проницаемости для ЖИГ-РТС в частотном диапазоне от $25 \mathrm{~Hz}$ до $1 \mathrm{MHz}$ представлены на рис. $2, a-d$. Спектры тангенса угла диэлектрических потерь в диапазоне частот от 100 до $1 \mathrm{MHz}$ и проводимости на переменном токе приведены на рис. $3, a, b$ соответственно.

Зависимости электрофизических параметров при двух фиксированных частотах (1 и $100 \mathrm{kHz})$ от температуры РТС приведены на рис. 4, $a-c$. Результаты измерения электропроводности на частотах 1 и $100 \mathrm{kHz}$ в температурном диапазоне $25-300^{\circ} \mathrm{C}$ представлены на рис. $5, a, b$.
Как и в случае измерений на постоянном токе, кривые характеризуются двумя областями. На вставке приведены значения энергии активации процесса проводимости, рассчитанной по формуле (1). Температурные зависимости диэлектрической проницаемости и тангенса угла диэлектрических потерь на частотах $1 \mathrm{kHz}$ и $100 \mathrm{kHz}$ приведены на рис. $6, a, b$.

\section{4. Обсуждение результатов}

Температурные зависимости электропроводности характеризуются двумя участками с разным наклоном, которые связаны с разными механизмами электропроводимости. Рассчитанные по участку II энергии активации, приведенные на вставке на рис. 1, показывают увеличение энергии активации с увеличением температуры РТС, начиная с $1350^{\circ} \mathrm{C}$. Стоит отметить, что значение сопротивления образца 6 , изготовленного по КТ, составляет $2.27 \cdot 10^{12} \Omega \cdot \mathrm{cm}$ и сравнимо по порядку со значениями $\rho$ образцов, изготовленных методом РТС при температурах спекания 1400 и $1450^{\circ} \mathrm{C}$. Кроме того, для образца 5 (температура спекания $1450^{\circ} \mathrm{C}$ ) энергия 

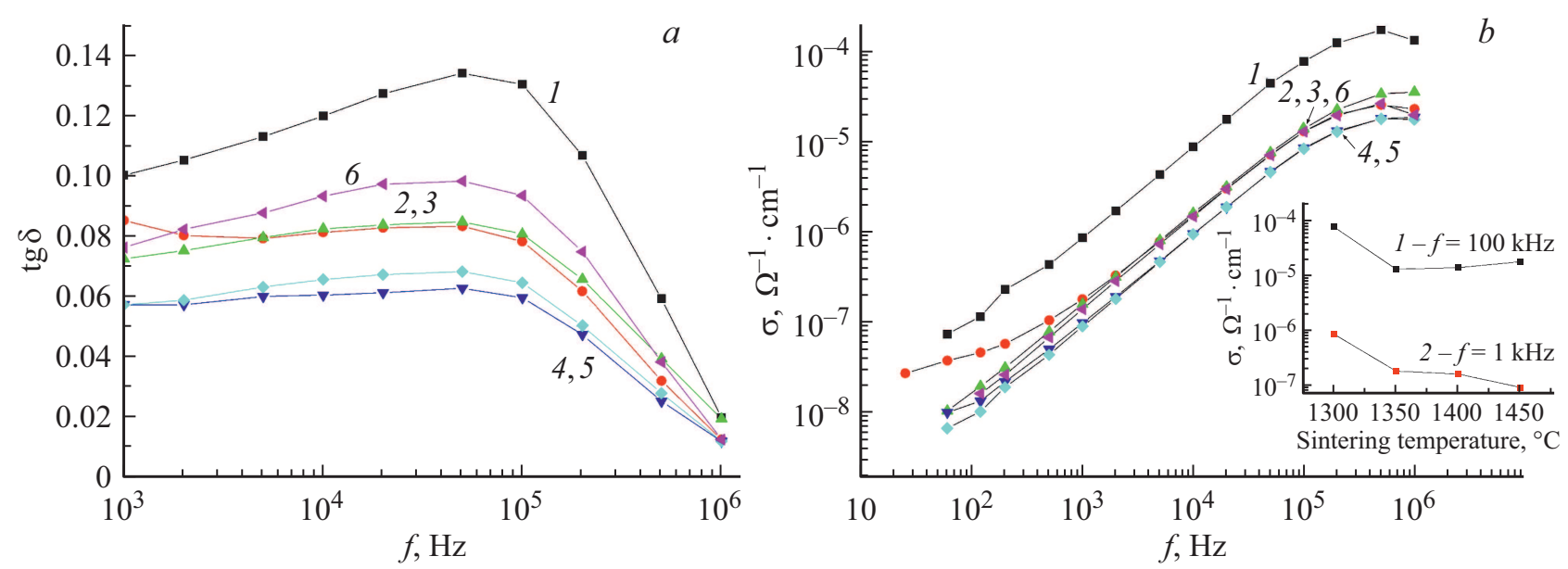

Рис. 3. Спектры тангенса угла диэлектрических потерь (a) и электропроводности на переменном токе $(b)$ для образцов $1-6$ при н. у.; на вставке - зависимость электропроводности на переменном токе при н. у от температуры спекания.
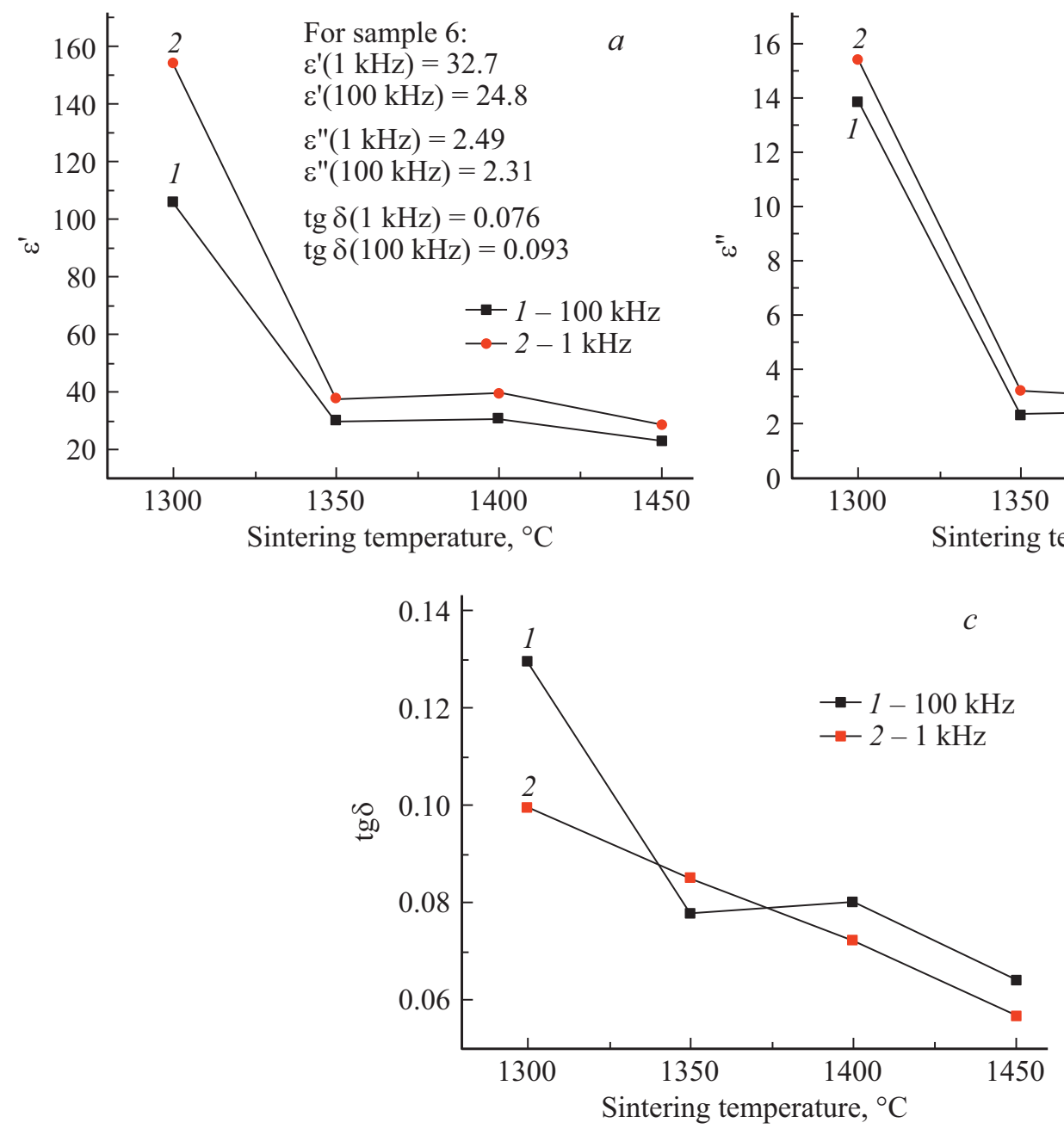

Рис. 4. Зависимость действительной части диэлектрической проницаемости, мнимой части диэлектрической проницаемости, тангенса угла потерь при н. у. от температуры спекания: $a-$ действительная часть диэлектрической проницаемости; $b-$ мнимая часть диэлектрической проницаемости; $c$ — тангенс угла потерь. 

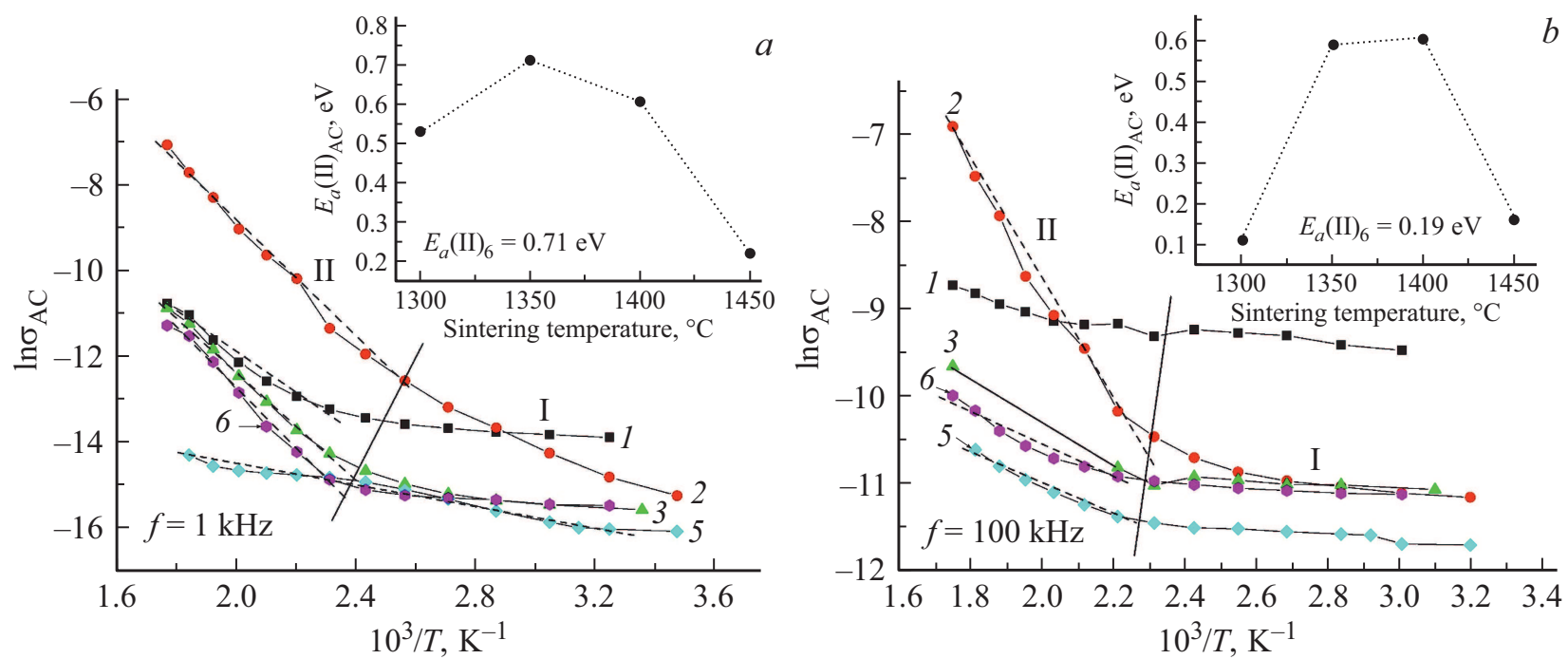

Рис. 5. Зависимость удельной электропроводимости на переменном токе $(1,100 \mathrm{kHz})$ от температуры в координатах Аррениуса для образцов $1-3,5-6$. На вставках зависимость энергии активации участка II от температуры PTC: $a-$ при частоте $1 \mathrm{kHz}$; $b-$ при частоте $100 \mathrm{kHz}$.
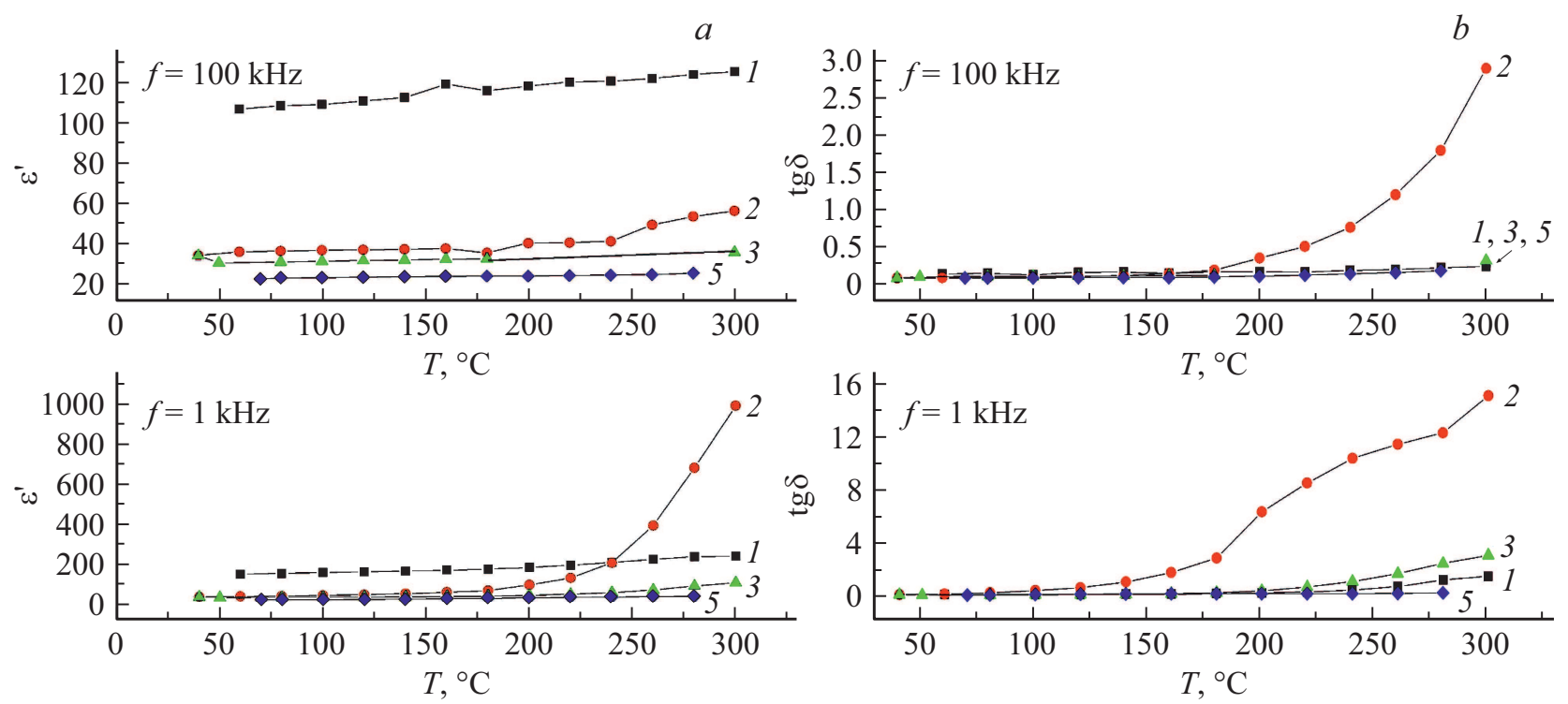

Рис. 6. Температурные зависимости действительной части диэлектрической проницаемости $(a)$ и тангенса диэлектрических потерь $(b)$.

активации составила $0.91 \mathrm{eV}$, что сравнимо с образцом, изготовленным по КТ, $(0.97 \mathrm{eV})$.

Для образца, спеченного при $1350^{\circ} \mathrm{C}$, несмотря на хорошие показатели микроструктуры, полученные мессбауэровскими исследованиями, значение электросопротивления меньше на два порядка по сравнению с образцами, изготовленными при 1400 и $1450^{\circ} \mathrm{C}$. Возможно, что причина малого сопротивления связана с наличием большой доли проводящей относительно зерен стекловидной фазы (межзеренной фазы). Если рассматривать температурные зависимости диэлектрической проницаемости и тангенса угла потерь, то ход кривых на частоте $1 \mathrm{kHz}$ для данного образца заметно выделяется резким ростом (рис. 6, a). Как показано в [12], такой рост характерен для аморфных стеклянных диэлектриков. Помимо этого, основной вклад в диэлектрические потери в керамических материалах вносят дефекты и стекловидная фаза. Ранее [13] было установлено, что в образце, полученном методом РТС при $1300^{\circ} \mathrm{C}$, из-за образования кислородных вакансий происходит оттягивание электронного облака у ионов железа $\mathrm{Fe}^{3+}$ в тетраэдрических позициях дефектами, что, в свою очередь, может приводить к появлению ионов железа с большей, чем „3+“ валентностью. Данный факт может указывать на то, что в феррите возможен прыжковый механизм электропроводности, при котором происходит скачко- 
образный переход между одноименными разновалентными ионами (например, $\mathrm{Fe}^{3+}$ и $\mathrm{Fe}^{4+}$ ). Таким образом можно объяснить различия более чем на два порядка электросопротивлений на постоянном токе в образцах, спеченных при 1300 и $1450^{\circ} \mathrm{C}$. В случае образцов 1400 и $1450^{\circ} \mathrm{C}$ высокие значения электросопротивления и энергии активации проводимости скорее всего связаны с более однородной микроструктурой, характеризующейся большим размером зерен, а следовательно, меньшим количеством дефектов и примесей, которые уменьшают ширину запрещенной зоны материала [16]. С помощью вышеописанных рассуждений также можно объяснить уменьшение значений комплексной диэлектрической проницаемости, проводимости на переменном токе и тангенса угла потерь при частотах 1 и $100 \mathrm{kHz}$ (рис. $3, a, b$, рис. $4, a-c$ ).

Спектры комплексной диэлектрической проницаемости (рис. $2, a-c$ ) и тангенса угла потерь (рис. $3, a$ ) при комнатной температуре показывают, что во всех образцах есть частотная дисперсия электрофизических параметров. Стоит отметить, что форма пика дисперсии тангенса угла потерь и мнимой диэлектрической проницаемости растянуты и ассиметричны, что может указывать на несколько процессов релаксации (поляризации). Также подтверждение этого предположения можно проследить по спектру на рис. $2, b$ (образец 2), на котором видно край пика мнимой части диэлектрической проницаемости в низкочастотной области (около $10 \mathrm{kHz}$ ). Так как структура поликристаллического феррита состоит из двух фаз (кристаллических зерен и межзеренных границ) с разной проводимостью, то дисперсию, с одной стороны, можно связать с поляризацией по механизму Максвелла-Вагнера для гетерогенных систем [17], которая описывает поляризацию на границе раздела двух сред с разными диэлектрическими параметрами. Характерной особенностью спектров образцов $1,3,4$ является то, что выше $\sim 1 \mathrm{kHz}$ вклад от поляризации МаксвеллаВагнера ослабевает. Похожие результаты можно видеть в работе [18].

С другой стороны, так как дисперсия проходит в частотном диапазоне до $1 \mathrm{MHz}$, то она может быть связана с тепловой ионной поляризацией, характеризующейся временем релаксации порядка $\sim 10^{-6} \mathrm{~s}$. Данный вид поляризации обусловлен ионной химической связью в кристаллической решетке ферритов.

Как и в случае с проводимостью на постоянном токе, температурные измерения проводимости на переменном токе при двух частотах 1 и $100 \mathrm{kHz}$ показывают, что на кривых можно выделить два участка. Энергия активации, рассчитанная на участке II, также характеризует изменение механизма проводимости. Однако зависимость энергии активации от температуры РТС проводимости на переменном токе проходит через максимум (как для 1 , так и для $100 \mathrm{kHz}$ ) (вставки на рис. $5, a, b$ ), в отличие от проводимости на постоянном токе - в этом случае энергия активации проходит через минимум (вставка на рис. 1).
Температурные зависимости диэлектрической проницаемости и тангенса угла диэлектрических потерь, приведенные на рис. $6, a, b$ соответственно, показывают, что для образца 5 (температура спекания $1450^{\circ} \mathrm{C}$ ) диэлектрическая проницаемость и тангенс угла потерь на частотах 1 и $100 \mathrm{kHz}$ меняются незначительно в диапазоне температур $25-300^{\circ} \mathrm{C}$. Для других образцов температурная зависимость имеет вид типичной для керамических материалов [12].

Сопоставление зависимостей электрофизических параметров и энергий активации от температуры РТС (рис. $1,3,4,5)$ позволяет сделать вывод о том, что при температурах синтеза $1400-1450^{\circ} \mathrm{C}$ электрические свойства образцов РТС ферритов-гранатов аналогичны свойствам образцов, полученных по КТ. Другой важной особенностью результатов измерений является то, что в образцах, полученных методом РТС с температурой $1450^{\circ} \mathrm{C}$ и выдержкой $5 \mathrm{~min}$, значения диэлектрической проницаемости, тангенса угла потерь (рис. $3, a$ ) и проводимости (рис. $3, b$ ) сравнимы с образцом, выполненным по КТ, или с образцом, изготовленным с помощью РТС при температуре спекания $1450^{\circ} \mathrm{C}$, выдержанным $30 \mathrm{~min}$. Это указывает на то, что уже при выдержке в течение 5 min возможно получение поликристаллов ЖИГ с приемлемыми электрофизическими параметрами. Таким образом, по сравнению с традиционной КТ, метод РТС обладает более высокими временной и энергоэффективностью.

\section{5. Заключение}

Методом диэлектрической спектроскопии и измерений сопротивления на постоянном и переменном токе изучены диэлектрические и электрофизические свойства поликристаллических образцов $\mathrm{Y}_{3} \mathrm{Fe}_{5} \mathrm{O}_{12}$, изготовленных по технологии РТС. Установлено, что удельное электросопротивление на постоянном и переменном токе возрастает с увеличением температуры спекания от 1300 до $1450^{\circ} \mathrm{C}$ с $4.86 \cdot 10^{9}$ до $3.54 \cdot 10^{12} \Omega \cdot \mathrm{cm}$ (для образца, изготовленного по КТ $\rho=2.27 \cdot 10^{12} \Omega \cdot \mathrm{cm}$ ). Температурные зависимости электропроводности характеризуются двумя участками в диапазоне температур $25-300^{\circ} \mathrm{C}$. Расчетные зависимости энергии активации процесса проводимости от температуры спекания на постоянном и переменном токе имеют разные тенденции: в случае постоянного тока кривая проходит через минимум; в случае переменного тока - через максимум. По спектрам комплексной диэлектрической проницаемости ЖИГ, полученных методом РТС, установлено, что в образцах имеется частотная дисперсия диэлектрической проницаемости, которая может быть обусловлена несколькими процессами поляризации. Показано, что с увеличением температуры спекания значения диэлектрической проницаемости, тангенса угла диэлектрических потерь и проводимости на переменном токе уменьшаются и при $1450^{\circ} \mathrm{C}$ достигают значений 
образца, выполненного по традиционной КТ. Образец поликристалла ЖИГ, полученного методом РТС при температуре спекания $1450^{\circ} \mathrm{C}$, характеризуется наибольшей температурной стабильностью диэлектрической проницаемости и тангенса угла диэлектрических потерь.

Таким образом, в настоящей работе методами диэлектрической спектроскопии и электрофизических исследований для поликристаллических ферритов еще раз подтверждена высокая энерго- и временная эффективность технологии РТС.

\section{Финансирование работы}

Исследование выполнено за счет средств гранта Российского научного фонда (соглашение № 19-19-00694 от 06.05.2019 г.).

\section{Конфликт интересов}

Авторы заявляют, что у них нет конфликта интересов.

\section{Список литературы}

[1] E.J.J. Mallmann, A.S.B. Sombra, J.C. Goes, P.B.A. Fechine. Solid State Phenom. 202, 65 (2013).

[2] Е.А. Васендина, Е.Н. Лысенко, В.А. Власов, А.Н. Соколовский, А.П. Суржиков, А.М. Притулов. Техника и технология силикатов 4, 6 (2011).

[3] Е.П. Найден, Р.В. Минин, В.И. Итин, В.А. Журавлев. Изв. вузов 56, 63 (2013).

[4] А.Н. Пашков, В.Г. Костишин, И.М. Исаев, А.С. Комлев, С.В. Щербаков, А.Г. Налогин, А.А. Алексеев, Е.А. Белоконь, А.А. Брязгин, М.В. Коробейников, М.А. Михайленко, А.В. Тимофеев. В сб.: XXIV Междунар. конф. „Электромагнитное поле и материалы (фундаментальные физические исследования)“. Инфра-М, М. (2016). С. 409.

[5] В.Г. Костишин, В.В. Коровушкин, Л.В. Панина, В.Г. Андреев, А.С. Комлев, Н.А. Юданов, А.Ю. Адамцов, А.Н. Николаев. Неорган. материалы 50, 1352 (2014).

[6] В.Г. Костишин, В.Г. Андреев, В.В. Коровушкин, Д.Н. Читанов, Н.А. Юданов, А.Т. Морченко, А.С. Комлев, А.Ю. Адамцов, А.Н. Николаев. Неорган. материалы 50, 1387 (2014).

[7] W.F.F. Wan Ali, N.S. Abdullah, M. Kamarudin, M.F. Ain, Z.A. Ahmad. Ceram. Int. 42, 13996 (2016).

[8] S.H. Vajargah, H.R.M. Hosseini, Z.A. Nemati. Mater. Sci. Eng. B 129, 211 (2006).

[9] S.D. Figueiro, E.J.J. Mallmann, J.C. Góes, N.M.P.S. Ricardo, J.C. Denardin, A.S.B. Sombra, P.B.A. Fechine. Exp. Polym. Lett. 4, 790 (2010).

[10] V. Sharma, J. Saha, S. Patnaik, B.K. Kuanr. J. Magn. Magn. Mater. 439, 277 (2017).

[11] F. Kremer, A. Schönhals. Broadband Dielectric Spectroscopy. Springer-Verlag, Berlin, Heidelberg (2003). 729 p.

[12] Г.И. Сканави. Диэлектрическая поляризация и потери в стеклах и керамических материалах с высокой диэлектрической проницаемостью. Гос. энерг. изд-во, М.-Л. (1952). $175 \mathrm{c}$.

[13] В.Г. Костишин, В.В. Коровушкин, А.Г. Налогин, С.В. Щербаков, И.М. Исаев, А.А. Алексеев, А.Ю. Миронович, Д.В. Салогуб. ФТТ 62, 1028 (2020).
[14] В.Г. Костишин, А.Г. Налогин, С.В. Щербаков, М.П. Мезенцева, М.А. Михайленко, М.В. Коробейников, Д.В. Салогуб, А.А. Брязгин. Изв. Юго-Западного гос. ун-та. Сер. Техника и технологии 8, 124 (2018).

[15] В.Г. Костишин, А.Г. Налогин, С.В. Щербаков, М.П. Мезенцева, М.А. Михайленко, М.В. Коробейников, А.А. Брязгин, К.В. Капранова. Изв. Юго-Западного гос. ун-та. Сер. Техника и технологии 7, 128 (2017).

[16] K.H.J. Buschow. Handbook of Magnetic Materials, 1st edn. Elsevier B.V., Amsterdam (2015). 460 p.

[17] Т.Л. Челидзе, А.И. Деревянко, О.Д. Куриленко. Электрическая спектроскопия гетерогенных систем. Наук. думка, Киев (1977). 232 с.

[18] Advanced Nanotechnologies for Detection and Defence against CBRN Agents. NATO Science for Peace and Security Series B: Physics and Biophysics / Eds S. Soreto Teixeira, A.J.M. Sales, M.P.F. Graça, M.A. Valente, L.C. Costa. In: P. Petkov, D. Tsiulyanu, C. Popov, W. Kulisch. Springer, Dordrecht (2018). P. 165.

Редактор Е.Ю. Флегонтова 